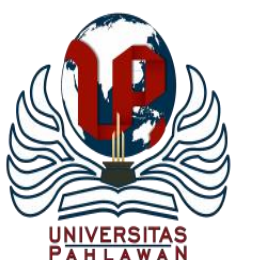

Jurnal Basicedu Volume 3 Nomor 4 Tahun 2019 Halaman 2159-2164

JURNAL BASICEDU

Research \& Learning in Elementary Education

https://jbasic.org/index.php/basicedu

\title{
UPAYA MENINGKATKAN HASIL BELAJAR MATEMATIKA MATERI PECAHAN DENGAN MENERAPAKAN MODEL DISCOVERY LEARNING
}

\author{
Dea Mukti Nanjelita ${ }^{1}$ \\ Universitas Kristen Satya Wacana, Jawa Tengah, Indonesia ${ }^{1}$ \\ Email : deamukti97@gmail.com ${ }^{1}$
}

\begin{abstract}
Abstrak
Dilaksanakannya penelitian ini bertujuan untuk meningkatkan hasil belajar matematika materi pecahan pada siswa kelas IV SD N Bandarjo 02 Ungaran dengan menerapkan model Discovery Learning. Pada proses pembelajaran digunakan langkah langkah model Discovery Learning yaitu, stimulus, problem statment, data collection, data processing, verivication, generalization. Jenis penelitian yang digunakan yaitu penelitian tindak kelas (PTK). pada saat pengamatan terhadap pembelajaran matematika belum menggunakan model yang tepat untuk siswa. Selain itu dari data yang didapat $62,5 \%$ atau 20 siswa mendapatkan nilai kurang dari 66. Kondisi tersebut dianggap belum mencapai KKM dan 37,5\% atau 12 siswa sudah mencapai KKM. Penelitian berlangsung selama 2 siklus dimana setiap siklus 3 kali pertemuan. Setelah diadakan tindakan siklus I hasil belajar siswa meningkat $75 \%$ atau sebanya 24 siswa yang telah mencapai KKM dan $25 \%$ atau 8 siswa beleum mencapai KKM. Pada tindakan siklus II hasil belajar siswa meningkat menjadi 84,375\% atau 27 siswa yang sudah mencapai KKM dan $15,625 \%$ atau 5 siswa yang belum mencapai KKM.
\end{abstract}

Kata kunci: Discovery Learning, Hasil Belajar, Matematika

\begin{abstract}
Abstrac
The implementation of this research aims to improve mathematics learning outcomes of fractional material in fourth grade students of SDN Bandarjo 02 Ungaran by applying the Discovery Learning model. In the learning process the steps of the Discovery Learning model are used, namely, stimulus, problem statements, data collection, data processing, verification, generalization. The type of research used is classroom action research (CAR). When observing mathematics learning, they have not used the right learning model for students. Besides that from the data obtained $62.5 \%$ or 20 students is got grades was less than 66. The condition was considered bellow Minimum Passing Grade and $37.5 \%$ or 12 students had already reached Minimum Passing Grade. The research lasted for 2 cycles where each cycle had 3 meetings. After the first cycle of action, student learning outcomes increased $75 \%$ or as many as 24 Minimum Passing Grade students and $25 \%$ or 8 students did not reach Minimum Passing Grade. In the second cycle of action student learning outcomes increased to $84.375 \%$ or 27 students who had reached Minimum Passing Grade and $15.625 \%$ or 5 students had reached those who had not yet reached Minimum Passing Grade.
\end{abstract}

Keywords: Discovery Learning, Learning Outcome, Mathematics

@ Jurnal Basicedu Prodi PGSD FIP UPTT 2019

$\triangle$ Corresponding author :

Address : Ungaran, Kab.Semarang

Email : deamukti97@gmail.com

ISSN 2580-3735 (Media Cetak)

Phone : ISSN 2580-1147 (Media Online) 


\section{PENDAHULUAN}

Tahun 2013/2014 kementrian pendidikan dan kebudayaan mulai memberlakukan kurikulum 2013. Kurikulum 2013 ini sebagai pengembangan dari kurikulum berbasis kompetensi (KBK) ditahun 2004 dan kompetensi tingkat satuan pendidikan (KTSP) ditahun 2006. Cakupan aspek sikap, pengetahuan, dan keterampilan. Kurikulum 2013 dalam pelaksanaannya menggunakan pendekatan saintifik.

Pendekatan saintifik merupakan prosedur yang dilandasi suatu metode ilmiah untuk mendapatkan pengetahuan. Sasaran pendekatan saintifik adalah pembelajaran sesuai dengan standar kompetensi lulusan dengan mengembangkan ranah sikap, pengetahuan, dan keterampilan. Standar proses pendidikan dasar dan menengah telah menerangkan perlunya proses pembelajarann yang mengacu pada pendekatan saintifik (Permendikbud nomor 65 tahun 2013). Pendekatan saintifik dapat diterapkan dalam proses pembelajaran dan dijadikan jembatan untuk mengembangkan ranah sikap, pengetahuan, dan keterampilan siswa (Budiyanto, 2016:2).

Salah satu pembelajaran yang dapat menerapkan pendekatan saintifik adalah matematika. Matematika adalah ilmu dasar yang dipelajari dan diberikan mulai dari sekolah dasar. Maka penting penguasaan konsep matematika yang benar sedini mungkin. Karena konsep dalam matematika saling mempengaruhi. Melalui pembelajaran matematika siswa diajak untuk berpikir logis agar dapat menerapkan dalam kehidupan sehari-hari.

Proses pembelajaran pada satuan pendidikan diselenggarakan secara interaktif, inspiratif, senang, menantang, siswa termotivasi untuk berpartisipasi aktif, mendapatkan ruang cukup untuk prakarsa, kreatif, dan kemandirian sesuai dengan bakat, minat, dan sesuai dengan perkembangan sidik maupun psikologi siswa (Permendikbud nomor 22 tahun 2016). Untuk itu tiap satuan pendidikan melaksanakan perencanaan pembelajaran, proses pembelajaran, dan penilaian proses pembelajaran guna meningkatkan efisiensi dan efektivitas ketercapaian kompetensi lulusan. Tujuan pembelajaran matematika di jenjang sekolah dasar yaitu mempersiapkan siswa menghadapi perubahan kehidupan dunia yang selalu berke,bang melalui latihan bertindak menggunakan kemampuan berpikir logis, analitis, sistematis, kritis, kreatif, serta dapat bekerja sama (BNSP,2006)

Kenyataannya pembelajaran dikelas tidak sesuai dengan tujuan pembelajaran matematika, karena materi yang disampaikan berupa informasi saja, dan pembelajaran didominasi oleh guru, sedangkan siswa aktif mencatat, sehingga terjadilah kegiatan menghafal konsep, jadi siswa tidak bisa menggunakan konsep matematika dalam masalah yang kompleksdengan melibatkan logika yang lebih tingga karena pemahaman konsepmatematika sendiri rendah (Wahyudi, 2014:2). Sejalan dengan tidak sesuainnya tujuan pembelajaran dengan penerapannya, ketidak berhasilah dalam pembelajaran, salah satunya peran guru lebih mendominasi sehingga menekan dan membatasi kebebasan aktivitas siswa, selain itu juga siswa menjadi penelan apa yang disajikan guru dan pada akhirnya menghambat potensi yang ada pada diri siswa (Tilaar, 2012:35).

Permasalah ini juga terjadi di SD $\mathrm{N}$ Bandarjo 02 Ungaran, pada saat pengamantan terhadap pembelajaran matematika belum menggunakan model yang tepat untuk siswa. Selain itu dari data yang didapat $62,5 \%$ atau 20 siswa mendapatkan nilai kurang dari 66 , kondisi tersebut dianggap belum mencapai KKM dan $37,5 \%$ atau 12 siswa sudah mencapai KKM.

Berdasarkan permasalah yang telah diuraikan, perlu diusahakan perbaikan 
pembelajaran yang sesuai dengan tuntutan kurikulum 2013 yang menekankan pada pendekatan saintifik. Pendekatan saintifik di kurikulum 2013 dijadikan sarana bagi siswa mencari pengetahuan secara mandiri, dengan lima tahapan yang masukan dalam kegiatan pembelajaran. Lima tahapan tersebut adalah $5 \mathrm{M}$ yang terdiri dari; mengamati, menanya, mencoba, menalar, dan mengkomunikasikan (Permendikbud No.103, 2014).

Sejalan dengan 5M pada proses pendekatan saintifik, model Discovery Learning juga berpusat pada proses pembelajaran siswa. Salah satu karakteristik model Discovery Learning siswa berperan sebagai ilmuan yang aktif dalam proses penemuan. Model Discovery Learning sangat cocok digunakan dalam proses pembelajaran, karena memiliki kelebihan dapat meningkatkan dan memperbaiki keterampilan, kognitif, dan menghapus rasa keraguan dari hasil penemuannya sendiri (Sylvi, 2015:15).

Berdasarkan penelitian sebelumnya oleh Wedekaningsih tentang penerapan model Discovery Learning untuk meningkatkan keterampilan berpikir kritis dan hasil belajar matematika peserta didik menunjukan hasil penelitian pada siklus I 52\% siswa mendapatkan nilai diatas KKM dan $48 \%$ siswa belum mencapai KKM. Setelah dilakuakn siklus II meningkat menjadi $87 \%$ siswa sudah mencapai KKM dan $13 \%$ siswa belum mencapai KKM

Berdasarkan uraian latar belakang, maka akan dilakukan penelitian Tindakan Kelas dengan kolabolari bersama dengan guru kelas IV yang bertujuan untuk meningkatkan hasil belajar matematika materi pecahan.

\section{METODE}

Jenis penelitian yang dilakukan adalah penelitian tindakan kelas (PTK). PTK merupakan upaya yang dapat dilakukan pendidik untuk meningkatkan kualitas dan tanggungjawab pengelolaan pembelajaran. Model yang digunakan dalam penelitian ini adalah spiral yang terdiri dari 4 tahap yang meliputi, perencanaan (planing), tidakan (action), pengamatan (observing), refleksi (reflecting), seperti pada gambar 1 .

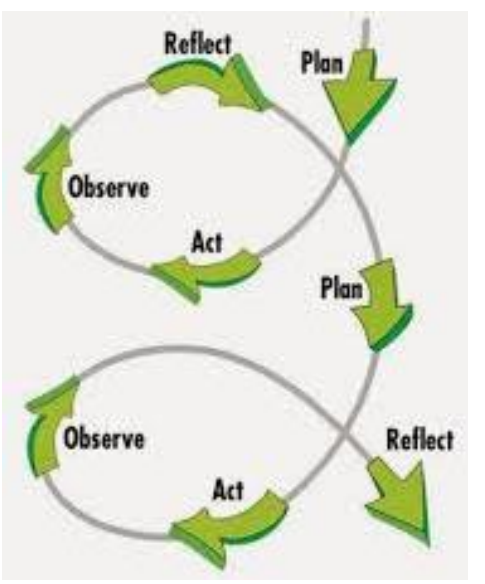

\section{Gambar 1}

Model penelitian C. Kemmis dan Mc. Taggart.

Subjek penelitian ini yaitu siswa kelas IV SD N Bandarjo 02 Ungaran, yang berjumlah 32 siswa yang terdiri dari 20 laki-laki dan 12 perempuan.

Variabel dalam penelitian ini terdiri dari variabel bebas (mempengaruhi) atau variabel $\mathrm{X}$ yaitu model Discovery Learning. Variabel terikat (dipengaruhi) atau variabel $\mathrm{Y}$ yaitu hasil belajar siswa. Penelitian ini dilakukan 2 siklus dimana setiap siklus terdiri dari 3 kali pertemuan yang masing-masing tiap pertemuan 3jam pelajaran (3x35menit).

Teknik pengumpulan data yang digunakan dalam penelitian ini adalah teknik tes dan non tes. Teknik tes ini sebagai alat ukur mengenai hasil belajar siswa. Teknik non tes yang digunakan adalah observasi menggunakan lembar observasi kegiatan pembelajaran dan kegiatan siswa, selain itu juga menggunakan dokumentasi yang berbentuk tulisan maupun gambar. Penelitian tindakan kelas ini dapat dinyatakan berhasil jika semua tahapan dalam model Discovery Learning dapat dilakukan sesuai urutan dengan baik dan 
hasil belajar siswa ataupun nilai-rata-rata kelas meningkat menjadi $\geq 80 \%$.

\section{HASIL DAN PEMBAHASAN}

Penelitian tindakan kelas ini dilakukan di SD N Bandarjo 02 Ungaran, dengan subjek yang diteliti siswa kelas IV berjumlah 32. Kondisi awal saat observasi pembelajaran matematika, belum menggunakan model pembelajaran yang tepat dan pembelajaran masih berpusat pada guru. Selain itu dari data yang didapat hasil belajar siswa kurang memuaskan ini dapat dilihat dari tabel 1.

Tabel 1

Rekapitulasi Hasil Belajar Matematika Kondisi

Awal

\begin{tabular}{|l|c|c|c|c|}
\hline \multirow{2}{*}{ No } & \multirow{2}{*}{ Nilai } & \multicolumn{2}{|c|}{ Kondisi Awal } & \multirow{2}{*}{ Keterangan } \\
\cline { 3 - 4 } & $<66$ & 20 & 62,5 & $\begin{array}{c}\text { Belum } \\
\text { mencapai } \\
\text { KKM }\end{array}$ \\
\hline 1 & $\geq 66$ & 12 & 37,5 & $\begin{array}{c}\text { Sudah } \\
\text { mencapai } \\
\text { KKM }\end{array}$ \\
\hline Jumlah & 32 & 100 & \\
\hline Rata-rata & \multicolumn{2}{|c|}{72,5} & \\
\hline KKM & \multicolumn{2}{|c|}{66} & \\
\hline $\begin{array}{l}\text { Nilai } \\
\text { tertinggi }\end{array}$ & \multicolumn{2}{|c|}{80} & \\
\hline $\begin{array}{l}\text { Nilai } \\
\text { terendah }\end{array}$ & \multicolumn{2}{|c|}{20} & \\
\hline
\end{tabular}

Data dari tabel 1 dapat diketahui terdapat $62,5 \%$ atau sebanyak 20 siswa mendapatkan nilai dibawah KKM, kondisi tersebut siswa masih belum mencapai KKM, dan hanya 37,5\% atau 12 siswa yang dianggap telah mencapai KKM.

Kegiatan penelitian siklusi I dilaksanakan 3 pertemuan masing-masing setiap pertemuan 3jam pelajaran (3 x 35menit). Kegiatan pembelajaran yang dilakukan pada siklus I setiap pertemuannya menggunakan sintak dari model Discovery Learning, mulai dari memberi stimulus terhadap siswa mengenai barang atau benda yang ada didalam kelas maupun dalam kehidupan sehari-hari yang dapat dipotong sama besar. Selanjutnya siswa mengidentifikasi masalah dengan kelompoknya (4-6 siswa) sesuai dengan rambu-rambu yang diberikan oleh guru. Siswa mengumpulkan data dengan cara melakukan percobaan menggunakan kertas bergambar. Setelah data yang diinginkn sudah terkumpul siswa mengolah data. Langkah selanjutnya siswa melakukan verivikasi data yang telah diolah lalu siswa dibantu dengan guru menyimpulkan hasil percobaan yang telah mereka lakukan. Setelah penelitian siklis I selesai didapatkan data yang dapat dilihat pada tabel 2 .

Tabel 2

Persentase Ketuntasan Hasil Belajar Siklus I

\begin{tabular}{|c|c|c|c|c|}
\hline \multirow{2}{*}{ No } & \multirow{2}{*}{ nilai } & \multicolumn{2}{|c|}{ Siklus I } & \multirow{2}{*}{ Keterangan } \\
\hline & & $\mathrm{F}$ & $\%$ & \\
\hline 1 & $<66$ & 8 & 25 & $\begin{array}{c}\text { Belum } \\
\text { Mencapai } \\
\text { KKM }\end{array}$ \\
\hline 2 & $\geq 66$ & 24 & 75 & $\begin{array}{c}\text { Sudah } \\
\text { Mencapai } \\
\text { KKM }\end{array}$ \\
\hline \multicolumn{2}{|c|}{ Jumlah } & 32 & 100 & \\
\hline \multicolumn{2}{|c|}{ Rata-rata } & \multicolumn{2}{|c|}{76,8} & \\
\hline \multicolumn{2}{|c|}{$\begin{array}{c}\text { Nilai } \\
\text { Tertinggi }\end{array}$} & \multicolumn{2}{|c|}{100} & \\
\hline \multicolumn{2}{|c|}{$\begin{array}{c}\text { Nilai } \\
\text { Terendah }\end{array}$} & \multicolumn{2}{|c|}{40} & \\
\hline
\end{tabular}

Dari data tabel 2 presentase ketuntasan hasil belajar siswa pada siklus I, dapat diketahui terdapat peningkat yang cukup signifikan yaitu mencapai $75 \%$ atau 24 siswa sudah mencapai KKM, dan mengalami penurunan siswa yang belum mencapai KKM 25\% atau sebanyak 8 siswa. Rata-rata nilai siswa juga mengalami kenaikan menjadi 76,8. Karena belum mencapai indikator keberhasilan maka dilanjut kan siklus berikutnya yaitu siklus II.

Kegiatan siklus II ini memperbaiki pembelajaran siklus I. Siklus II dirancang dan dilakukan berdasarkan dari hasil refleksi dan evaluasi pada siklus I. Perbaikan yang perlu dilakukan diantaranya guru perlu menerangkan kegiatan yang harus dilakukan siswa secara detail, agar siswa tidak merasa bingung. Mengurangi jumlah anggota kelompok agar kelas tetap 
2163 Upaya meningkatkan hasil belajar matematika materi pecahan dengan menerapkan model discovery learning - Dea Mukti Nanjelita

kondusif. Memberikan arahan berupa tulisan dan juga lisan agar siswa betul-betul paham dengan kegiatan percobaan yang dilakukan, guru sebagai fasilitator harus dapat memancing pengetahuan siswa agar berani untuk bertanya dan mengemukakan pendapat saat berdiskusi atau maju kedepan kelas. Siklus II ini juga menggunakan sintak dari model Discovery Learning dengan memperhatikan refleksi dan evaluasi yang sudah dilakukan. Setelah siklus II dilakukan, hasil belajar siswa meningkat. Hasil tersebut dapat dilihat pada tabel 3 .

\section{Tabel 3}

\section{Persentase Ketuntasan Hasil Belajar Siklus I}

\begin{tabular}{|c|c|c|c|c|}
\hline \multirow{2}{*}{ No } & \multirow{2}{*}{ Nilai } & \multicolumn{2}{|c|}{ Siklus II } & Keteranga \\
\cline { 3 - 4 } & $<$ & $\mathrm{F}$ & $\%$ & $\mathrm{n}$ \\
\hline 2 & 5 & $\begin{array}{c}15,62 \\
5\end{array}$ & $\begin{array}{c}\text { Belum } \\
\text { Mencapai } \\
\text { KKM }\end{array}$ \\
\hline 266 & 27 & $\begin{array}{c}84,37 \\
5\end{array}$ & $\begin{array}{c}\text { Sudah } \\
\text { Mencapai } \\
\text { KKM }\end{array}$ \\
\hline \multicolumn{2}{|c|}{ Jumlah } & 32 & 100 & \\
\hline \multicolumn{2}{|c|}{ Rata-rata } & \multicolumn{2}{|c|}{84,06} & \\
\hline \multicolumn{2}{|c|}{ Nilai Tertinggi } & \multicolumn{2}{|c|}{100} & \\
\hline \multicolumn{2}{|c|}{ Nilai Terendah } & \multicolumn{2}{|c|}{50} & \\
\hline
\end{tabular}

Dapat dilihat tabel 3 presentase ketuntasan hasil belajar siswa pada siklus II, menunjukkan adanya peningkatan, 84,375\% atau 27 siswa yang telah mencapai KKM. Sedangkan 15,625\% atau 5 siswa belum mencapai KKM dan rata-rata nilai siswa mencapai 84,06. Karena pada siklus ini sudah melampaui indikator keberhasilan, maka penelitian tindakan kelas dihentikan sampai siklus II.

Setelah dilakukan penelitian dan pada setiap siklusnya selalu mengalami peningkatan dari pra siklus hingga siklus II berakhir. Berikut ini perbandingan hasil belajar siswa dari pra siklus, siklus I, siklus II dapat diliat tabel 4.
Tabel 4

Tabel Perbandingan Persentase Ketintansan Belajar Pra Siklus, Siklus I, SiklusII

\begin{tabular}{|c|c|c|c|c|c|c|c|}
\hline \multicolumn{2}{|c|}{$\begin{array}{c}\text { Standar } \\
\text { ketuntasan }\end{array}$} & \multicolumn{2}{|c|}{$\begin{array}{c}\text { Pra } \\
\text { Siklus }\end{array}$} & \multicolumn{2}{c|}{ Siklsu I } & \multicolumn{2}{c|}{ Siklus II } \\
\hline nilai & ket & F & $\%$ & F & $\%$ & F & $\%$ \\
\hline$<66$ & $\begin{array}{c}\text { Belum } \\
\text { mencapai } \\
\text { KKM }\end{array}$ & 20 & 62,5 & 8 & 25 & 5 & 15,6 \\
\hline $\begin{array}{c}\text { Sudah } \\
\text { mencapai } \\
\text { KKM }\end{array}$ & 12 & 37,5 & 24 & 75 & 27 & 84.2 \\
\hline \multicolumn{2}{|c|}{ Jumlah } & 32 & 100 & 32 & 100 & 32 & 100 \\
\hline \multicolumn{2}{|c|}{ Rata-rata } & \multicolumn{2}{|c|}{72,5} & 76,8 & \multicolumn{2}{c|}{84.06} \\
\hline \multicolumn{2}{|c|}{ Nilai Teringgi } & \multicolumn{2}{|c|}{80} & \multicolumn{2}{c|}{100} & \multicolumn{2}{c|}{100} \\
\hline \multicolumn{2}{|c|}{20} & \multicolumn{2}{c|}{40} & \multicolumn{2}{c|}{50} \\
\hline
\end{tabular}

Dilihat dari tabel 4, menunjukan model Discovery Learning dapat meningkat hasil belajar siswa, ini terbukti dari saat pra siklus terdapat $62,5 \%$ atau 20 siswa yang belum mencapai KKM dan terdapat $37,5 \%$ atau 12 siswa yang sudah mencapai KKM. Setelah dilakukan tindakan pada siklus I tedapat peningkatan siswa yang sudah mencapai KKM 75\% atau 24 siswa, penurunan pada siswa yang mendapat nilai dibawah KKM $25 \%$ atau sebnyak 8 siswa. Begitu juga terjadi pada siklus II mengalami peningkatan siswa yang sudah mencapai KKM 84,375\% dan siswa yang belum mencapai KKM mengalami penurunan $15,625 \%$. Hal ini dapat dilihat pada gambar 2 diagram perbandingan ketuntasan hasil belajar.

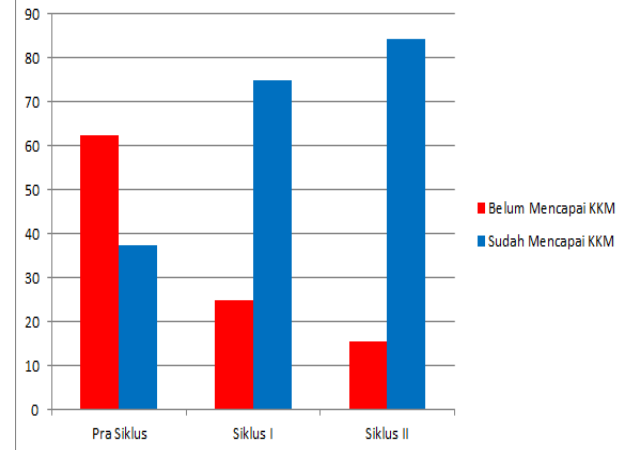

Gambar 2

Diagram Perbandingan Ketuntasan Hasil

Belajar Pra siklus, Siklus I, Siklus II 


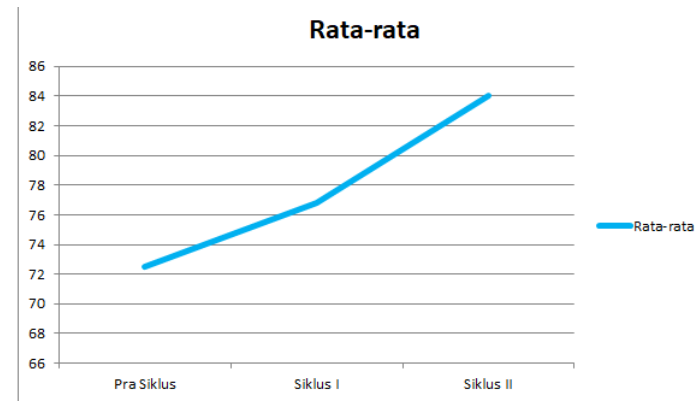

Gambar 3

Grafik perbandingan skor maksimal perbandingan rata-rata saat pra siklus, siklus I, siklus II

Dilihat dari tabel 4 dan gambar 3 grafik perbandingan rata-rata saat pra siklus, siklus I, siklus II, menunjukan setiap siklusnya meningkat yaitu pra siklus 72,5, siklus I 76,8, dan di siklus II menjadi 84,06.

\section{SIMPULAN}

Berdasarkan hasil penelitian dan pembahasan yeng telah dilakukan pada penelitian tindakan kelas yaitu siklus I dan II, maka dapat disimpulkan bahwa model Discovery Learning dapat meningkatkan hasil belajar matematika materi pecahan melalui langkah-langkah (sintak) model Discovery Learning. Dimana setelah dilakukan tindakan siklus I hasil belajar siswa meningkat menjadi $75 \%$ atau sebanyak 24 siswa sudah mencapai KKM. Disiklus II juga terjadi peningkatan menjadi 84,375\% atau sebanyak 27 siswa yang sudah mencapai KKM. Selain itu ratarata nilai siswa meningkat dari siklus I 76,8 dan di siklus II menjadi 84,06. Dari simpulan diatas, disarankan untuk guru dapat menerapkan model Discovery Learning pada pembelajaran untuk meningkatkan hasil belajar siswa dalam muatan pelajara matematika.

\section{DAFTAR PUSTAKA}

Baharudin \& Wahyuni, E. (2008). Teori Belajar Dan Pembelajaran. Sleman, Jogjakarta: AR_RUZZ.
BNSP. (2006). PP No. 22 Tahun 2006 Tentang Standar Isi SD/MI. Indonesia: Depdiknas

Budianto, A. (2016). Sintaks 45 Metode Pembelajaran Dalam Student Centered Learning (Scl). Malang: Universitas Muhammadiyah Malang Perss.

Hosnan. (2014). Pendekatan Saintifik Dan Kontekstual Dalam Pembelajaran Abad 21. Bogor: Ghalia Indonesia.

Illahi,M.T. (2014). Penerapan Model Discovery Learning Dan Mental Vacational Skill. Jogjakarta: Diva Perss

Permendikbud. (2014). Peraturan Menteri Pendidikan Dan Kebudayaan No.103 Tahun 2014 pasal 2 ayat 7 dan 8 Tentang Pembelajaran Pada Pendidikan Dasar Dan Menengah. Jakarta: Kemendikbud

Permendikbud. (2016). Nomor 22 Tahun 2016 Tentang Standar Proses Pendidikan Dasar dan Menengah. Jakarta: Kemendikbud

Rahyubi, H. (2012). Teori Belajar Dan Aplikasi Pembelajaran Motorik. Bandung, Jawa Barat: Nusa Media.

Ruumini \& Wardani, N.S. (2016). Upaya Peningkatan Hasil Belajar Tema berbagai Pekerjaan Melalui Model Discovery Learning Siswa kelas 4 SDN Kutoharjo 01 Pati Kabupaten Pati Semester 1 Tahun Ajaran 2014-2015. SCHOLARIA, vol. 6, no. 1

Sudjana, N. (2011). Dasar-Dasar Proses Belajar Mengajar. Bandung: Sinar Baru Algensinda.

Suprijono, A. (2011). Cooperative Laerning Teori dan Aplikasi Paikem. Yogyakarta: Pustaka Belajar

Wardani, N.S, dan Slameto. (2012). Evaluasi Proses dan Hasil Belajar. Salatiga: Widya Sari Perss

Wedekaningsih, A. (2019). Penerapan Model Pembelajaran Discovery Learning Untuk Meningkatkan Keterampilan Berpikir Kritis Dan Hasil Belajar Matematika Peserta Didik. BASICEDU, vol. 3, no.1 